\title{
Photodynamic therapy: a promising new modality for the treatment of
} cancer

\author{
J.J. Schuitmaker ${ }^{\text {a,* }}$, P. Baas ${ }^{\text {b }}$, H.L.L.M. van Leengoed ${ }^{\text {c }}$, F.W. van der Meulen ${ }^{\text {d }}$, W.M. Star ${ }^{\mathrm{e}}$, \\ N. van Zandwijk ${ }^{\mathrm{b}}$ \\ a Department of Ophthalmology, Academic Hospital of the University of Leiden, Sylvius Laboratory, Wassenaarseweg 72, 2333 AL Leiden, Netherlands \\ ${ }^{\circ}$ Department of Medical Oncology, Netherlands Cancer Institute, Plesmanlaan 121. 1066 CX Amsterdam, Netherlands \\ ${ }^{c}$ Department of Dermatology, Roswell Park Cancer Institute, Elm \& Carlton Streets, Buffalo, NY, 14263-0001 USA \\ a Department of Otolaryngology and Laser Centre, Academic Medical Centre, Meibergdreef 9, 1105 Amsterdam, Netherlands \\ ${ }^{e}$ Daniel den Hoed Cancer Centre, Department of Clinical Physics, PO Box 5201, 3008 AE Rotterdam, Netherlands
}

Received 8 March 1996; accepted 3 April 1996

\begin{abstract}
The first reports on photodynamic therapy (PDT) date back to the 1970s. Since then, several thousands of patients, both with early stage and advanced stage solid tumours, have been treated with PDT and many claims have been made regarding its efficacy. Nevertheless, the therapy has not yet found general acceptance by oncologists. Therefore it seems legitimate to ask whether PDT can still be described as "a promising new therapy in the treatment of cancer".

Clinically, PDT has been mainly used for bladder cancer, lung cancer and in malignant diseases of the skin and upper aerodigestive tract. The sensitizer used in the photodynamic treatment of most patients is Photofrin $₫$, (Photofrin $₫$, the commercial name of dihematoporphyrin ether/ester, containing $>80 \%$ of the active porphyrin dimers/oligomers (A.M.R. Fisher, A.L. Murphee and C.J. Gomer, Clinical and preclinical photodynamictherapy, Review Series Article, Lasers Surg. Med., 17 (1995) 2-31). It is a complex mixture of porphyrins derived from hematoporphyrin. Although this sensitizer is effective, it is not the most suitable photosensitizer for PDT. Prolonged skin photosensitivity and the relatively low absorbance at $630 \mathrm{~nm}$, a wavelength where tissue penetration of light is not optimal, have been frequently cited as negative aspects hindering general acceptance. A multitude of new sensitizers is currently under evaluation. Most of these "second generation photosensitizers"' are chemically pure, absorb light at around $650 \mathrm{~nm}$ or greater and induce no or less general skin photosensitivity. Another novel approach is the photosensitization of neoplasms by the induction of endogenous photosensitizers through the application of 5aminolevulinic acid (ALA). This article addresses the use of PDT in the disciplines mentioned above and attempts to indicate developments of PDT which could be necessary for this therapy to gain a wider acceptance in the various fields.
\end{abstract}

Keywords: Photodynamic therapy; Cancer; 5-Aminolevulinic acid; Photosensitizers; Photofrin ${ }^{\circledR}$

\section{Introduction}

Photodynamic therapy (PDT) has been designated as a "promising new modality in the treatment of cancer" since the early 1980s. This can be partly attributed to the very attractive basic concept of PDT; the combination of two therapeutic agents, a photosensitizing drug and light, which are relatively harmless by themselves but combined (in the presence of oxygen) ultimately cause more or less selective tumour destruction. Nevertheless, PDT has not yet been widely accepted by practising oncologists.

The clinical areas for which Photofrin $\$$-based PDT has been predominantly used are superficial bladder cancer, lung

\footnotetext{
* Corresponding author.
}

cancer and in cancer of the skin and upper aerodigestive tract. To date, this therapy has been approved in Canada for the prophylactic treatment of recurrent papillary bladder cancer and for the reduction of obstruction and palliation of dysphagia in patients with completely or partially obstructing oesophageal cancer. In the Netherlands it has been approved for obstructive, and early lung and oesophageal cancer and in Japan for early stage lung, gastric and cervical cancer (including cervical dysplasia), and superficial oesophageal and gastric cancer. Recently, the US Food and Drug Administration (FDA) approved Photofrin ${ }^{\circledR}$ for palliative treatment of patients with totally obstructing tumors and partially obstructing oesophageal cancers that are unsuitable for treatment with thermal laser therapy. The FDA approval includes clearance 
for a number of specific laser systems and a fibre optic used to activate the sensitizer.

Using a "standard" protocol (drug dose of 2-5 mg kg $\mathrm{bw}^{-1}$ (bw, body weight) and 100-200 $\mathrm{J} \mathrm{cm}^{-2}, 24-72 \mathrm{~h}$ after intravenous administration) Photofrin $\circledast$ is an effective photosensitizer in most cases. However, it is not the most suitable photosensitizer for PDT due to the prolonged skin photosensitivity it induces and the relatively low absorbance at 630 $\mathrm{nm}$, a wavelength where tissue penetration of light is not optimal. All patients who have received Photofrin (8) are photosensitive and are usually advised to protect themselves from exposure to sunlight or bright lights for a period of four to eight weeks. Only a few studies have addressed this photosensitivity specifically. Most of these studies have been based on retrospective (by means of interview and/or questionnaire) surveys [1], and follow-ups of treatments using relatively high drug doses [2,3]. Photosensitivity testing was reported in two studies. One was based on sequential weekly phototesting [4] but again using a relatively high drug dose (2-5 $\mathrm{mg} \mathrm{kg}^{-1}$ ). The second study showed a dose-dependent relationship between drug dose and cutaneous photosensitivity [5]. Therefore, it is to be expected that reducing the drug dose to $1 \mathrm{mg} \mathrm{kg}^{-1}$ [6], will reduce the duration of the cutaneous photosensitivity. Apart from the kinetics of the photosensitizer in the skin, the skin type and the compliance of the patient with the provided instructions will significantly influence the length and severity of the photosensitivity period.

Second generation photosensitizers are chemically pure, absorb light at around $650 \mathrm{~nm}$ or longer and induce (with drug doses usually applied for PDT) no, or significantly less, general skin photosensitivity. Increasing the wavelength at which sensitizers can be photoactivated not only allows the treatment of larger tissue volumes but also allows the possibility of using new light sources such as light emitting diodes (LEDs) and laserdiodes. A few candidates currently under clinical investigation are: benzoporphyrin derivative monoacid ring A (BPD-MA, $\lambda=690 \mathrm{~nm}$ ), mono-l-aspartyl chlorin e6 (NPe6, $\lambda=654 \mathrm{~nm}$ ), tin ethyl etiopurpurin $\left(\mathrm{SnET}_{2}\right.$, $\lambda=660 \mathrm{~nm}$ ) and meta-tetra(hydroxyphenyl)chlorin (mTHPC, $\lambda=652 \mathrm{~nm}$ ). Apart from the properties mentioned, it must be proven for every new second generation photosensitizer that it is at least as efficient in eradicating tumors as Photofrin $B$ which still must be viewed as the gold standard for photodynamic therapy. A recent development is the photosensitization of tumors by endogenous induction of photosensitizers through the topical or systemic application of 5-aminolevulinic acid (ALA) [7]. ALA is the metabolic precursor of protoporphyrin IX (PpIX) in the biosynthetic pathway to haem. In contrast to ALA, PpIX is photodynamically active and so can act as an endogenous photosensitizer. High complete response rates and excellent cosmetic results have been reported, especially when treating superficial basal cell carcinomas in the head and neck region [8].

This article addresses the use of (mainly) Photofrin®based PDT in superficial bladder cancer, lung cancer and in diseases of the skin and upper aerodigestive tract. Clinically, these are the areas for which this therapy has been chiefly used. Furthermore, an attempt will be made to indicate future developments of PDT which could be necessary for this therapy to gain a wider acceptance in the various fields.

\section{Photodynamic therapy of superficial bladder cancer}

\subsection{Introduction and early clinical results}

Of patients diagnosed with bladder cancer, 75-80\% initially present with superficial tumours. The primary form of treatment is transurethral resection (TUR), but recurrences occur in $40-80 \%$ of cases. Intravesical chemotherapy or immunotherapy (with Bacillus Calmette-Guérin (BCG)) is applied to prevent or delay recurrence, with a $60-70 \%$ response rate [9]. Bladder cancers account for approximately $3 \%$ of all malignant diseases. Of all bladder cancers, $75 \%$ are (uni) focal and show a low rate of progression, so that TUR is an adequate treatment. A small fraction (2\%) is true carcinoma in situ (CIS), which is resistant to conventional treatment modalities and has a high risk of progression. The remainder $(23 \%)$ of patients has multifocal disease and CIS may also be present.

Since visible light does not penetrate deeply into tissue, PDT is most effective in the treatment of superficial cancer. Therefore, PDT appears to be an attractive treatment alternative for superficial bladder cancer. The initial experience with PDT in the bladder has been reviewed by a number of authors $[10-12]$. The first patients were treated with focal illumination, with good response rates, but it was soon realized that the potential of PDT would be optimally exploited only by whole bladder wall irradiation. The purpose of PDT treatment of superficial bladder cancer is twofold: eradication of visible and invisible disease and prevention of recurrence after TUR. Basically, the whole bladder wall is at risk of developing new tumours. Therefore, a photosensitizer which is preferentially retained in malignant and pre-malignant tissue, combined with uniform irradiation of the bladder wall, could ideally yield complete tumour destruction with sparing of normal mucosa. In clinical practice, it has been found that whole bladder wall PDT can be effective against superficial bladder cancer, but the side effects are not negligible [1317]. Apart from Photofrin $®$ induced skin photosensitivity, the most important side effects are increased urinary frequency, urgency and bladder spasm. Reduction in bladder capacity is generally temporary. The most serious complication is permanent bladder contraction, which is probably an indication of overdosage [12].

\subsection{Light delivery and light dosimetry for whole bladder PDT}

The full potential of whole bladder PDT can only be achieved with optimum light delivery and light dosimetry. 
The most common device for light delivery is a spherical diffuser mounted on the tip of an optical fibre connected to a laser. The diffuser should emit light uniformly in all directions and should be placed at the centre of the bladder. This is usually done with the help of intravesical ultrasound, which is not easy, since the bladder is not a sphere [18], this method is not very sensitive and gives no information about the light distribution. A small displacement of the diffuser from the optimum position can lead to a large non-uniformity in the light dose [19] which could cause complications [14]. Jocham, Unsöld and coworkers [13,20,21] have developed special catheters and balloons to ensure uniform light delivery. Nseyo et al. [18] have developed a balloon that forces the bladder into a sphere with the diffuser at its centre. In this way uniform illumination is guaranteed. However, this does not guarantee that the same light dose is delivered to each patient because the scattered part of the light dose differs between patients. Marijnissen et al. [19] have developed a system providing in situ light dosimetry, for optimum placement of the diffuser and to measure the true light dose. Most authors have reported the light dose to the bladder wall in terms of non-scattered light, calculated from the power emitted by the diffuser. Clinical in situ measurements have shown a large effect of scattered light, so that the total light dose is on the average 5 times the non-scattered light dose. If the non-scattered light dose is reported to be $15 \mathrm{~J} \mathrm{~cm}^{-2}$, then the true light dose is on average $75 \mathrm{~J} \mathrm{~cm}^{-2}$. A further complication is that the contribution of scattered light differs between patients. The ratio between total and non-scattered light dose was found to vary between 2.5 and 7.1 [22] and these experimental data were confirmed by calculations using measured optical properties [23]. It thus appears that in situ light dosimetry is indispensable.

\subsection{Recent clinical results and possible improvements}

Although there is agreement that PDT has potential in the treatment of superficial bladder cancer, recent long term follow-up results are no better than the instillation of BCG or chemotherapeutic drugs $[13,17]$, not even when in situ dosimetry was performed. Furthermore, the side effects are considerable [24]. Thus the question arises whether the therapeutic ratio can be improved. One possibility is lowering of the administered Photofrin ${ }^{\circledR}$ dose, which is mostly $2 \mathrm{mg}$ $\mathrm{kg}^{-1}$. Studies on PDT of skin cancer have shown that $1 \mathrm{mg}$ $\mathrm{kg}^{-1}$ Photofrin ${ }^{\circledR}$ combined with a higher light dose yields an improved therapeutic ratio [7]. The same may be possible in PDT of bladder cancer. Recently, Jocham [25] has designed a phase III study to compare PDT using $1.5 \mathrm{mg}$ $\mathrm{kg}^{-1}$ Photofrin (8) against instillation of BCG. The distribution of sulphonated aluminium phthalocyanine (AIPcS) in rat bladder tissue suggests that PDT with this drug may yield a better therapeutic ratio than with Photofrin $\otimes[26]$. Instillation of a photosensitizer in the bladder would avoid the problem of induced skin photosensitivity, but experiments suggest that the therapeutic effect of PDT is insufficient, both after instillation of AIPcS [26] and Photofrin ${ }^{\circledR}$ [27]. Recently, endogenous photosensitization after application of 5-aminolevulinic acid (ALA) has been used effectively in PDT of superficial human skin cancer [7]. Experimental results with rats indicate that this method may also be effective in the bladder [28]. This was recently confirmed in clinical treatments of patients with superficial bladder cancer $[29,30]$. The side effects of PDT in the bladder, e.g. dysuria and pollakisuria, seem to be less after ALA-PDT rather than after Photofrin ${ }^{\circledR}$-PDT. Reduction of bladder capacity has not yet been observed [29,30]. In summary; there are still many ways to improve PDT of bladder cancer.

\subsection{Detection of bladder cancer by photosensitizer induced fluorescence}

Since superficial bladder cancer is often not cystoscopically visible, fluorescence detection based on preferential drug retention is very attractive. The usefulness of Photofrin ${ }^{\circledR}$ fluorescence for cancer detection in the bladder has been demonstrated in both experimental animals [31] and clinically [32]. Instillation of ALA is also very promising in this respect [33]. The sensitivity of ALA-induced fluorescence for detection of superficial bladder cancer is approaching $100 \%$, compared with $73 \%$ for white light cytoscopy. However, ALA-induced fluorescence has not improved the specificity $(\approx 65 \%)$ [34]. If the specificity of fluorescence cytoscopy can be improved, this method has potential for use in routine clinical practice. No other drugs have been studied for fluorescence detection of bladder cancer.

\section{Photodynamic therapy of lung cancer}

\subsection{Introduction}

Despite major advances over the past 40 years in the field of surgery, radiation therapy and more recently chemotherapy, the failure rate of lung cancer treatment remains unacceptably high. One interpretation of the apparent lack of overall progress in recent years is that currently available approaches to lung cancer treatment are being used at close to optimal levels. In addition, efficient techniques for early diagnosis of local and metastatic (sub-clinical) disease are lacking. Virtually all approaches to further improve the treatment of lung cancer have been empirical and unfortunately there is still little collaboration between clinicians and basic scientists. In this respect, PDT is attractive [35] in that it requires only minimally invasive techniques (flexible bronchoscopy), it may be repeated several times and, apart from skin photosensitivity, is not accompanied by significant morbidity. It is estimated that more than one thousand lung cancer patients have been treated with PDT. The standard treatment protocol involves intraveneous (iv.) injection of a photosensitizing agent (usually Photofrin (, $2 \mathrm{mg} \mathrm{kg}^{-1}$ bw for lung cancer), followed $24-48 \mathrm{~h}$ later by exposure to laser light 
(200-400 $\mathrm{mW} \mathrm{cm}^{-1}$ diffuser, $100-200 \mathrm{~J} \mathrm{~cm}^{-1}$ ) at the activating wavelength.

\subsection{PDT in early stage lung cancer}

At the Tokyo Medical College Hospital, Kato et al. [36] used hematoporphyrin derivative (HPD) to treat 30 lesions in 26 patients with early stage (stage Ia according to the UKC classification) non-small cell lung cancer (NSCLC). All lesions showed a complete response after treatment as confirmed by histology and cytology. Malignancy recurred in only three lesions. After an average follow-up period of 39.5 months, 16 patients were alive and apparently free of disease, three having survived for more than five years and one for eight years. The best results were obtained in those patients where endoscopically the tumour appeared to be relatively small and confined to one or two (sub) segmental bronchi [37].

In the Mayo Clinic, 13 patients presenting with NSCLC were considered surgical candidates before PDT was performed [38-40]. The patients were treated with the understanding that if there was residual cancer after no more than two sessions of PDT, performed at three month intervals, they would receive surgical therapy. In this group of 13 patients, $12(92 \%)$ achieved a complete response. Ten (76\%) revealed a complete response after the first photodynamic treatment, two other patients after the second treatment. Of the 12 lesions in which a complete response was obtained, three (25\%) recurred during the first two years of follow-up. Two of them could be surgically resected and one underwent a third PDT treatment and demonstrated, again, a complete response.

At the Netherlands Cancer Institute, 10 out of 11 patients with stage I NSCLC achieved a complete response with PDT (using Photofrin $($ ) [41]. The only remaining patient achieved a partial response, still showing carcinoma in situ after a second treatment. This series of patients was not restricted to "early stage" patients and differed from the Mayo series in that 10 out of 11 cases were not considered surgical candidates as a consequence of poor pulmonary function.

A recent publication on PDT in early stage lung cancer from Furuse et al. [42] confirms the excellent effects of PDT in 54 patients with centrally located early stage lung cancer, who have limited tumour invasion extending over a small area of the bronchial tree (preferably $\leq 1 \mathrm{~cm}$ ). With the present technology, the indication for PDT in early stage lung cancer may be summarized according to Kato [42]: "the lesion should be visible endoscopically and it should be possible to recognize the peripheral margin of the tumour, submucosal tumour invasion should be limited to within the bronchial cartilage and the lesion should be able to be photoirradiated from a $90^{\circ}$ angle".

\subsection{PDT in advanced lung cancer}

The results of the series of patients with advanced locoregional disease reported so far are more difficult to interpret. By definition they include patients with a variety of prognostic factors such as all kinds of combinations of tumour and lymph node (TN) status, performance score and weight loss. During follow-up, a significant proportion of the test population will also present with distant metastases, in some cases shortly after locoregional treatment. Local control can not be evaluated as rigidly and survival figures should be interpreted with caution. Moreover, the assessment of response in patients with advanced disease is quite complicated. It is frequently hampered by the difficulties of combining the outcome of chest roentgenology (including CT-scan) with the results obtained by bronchoscopy. Nevertheless, in all series (partial) response rates are fairly high [43].

Major complications associated with PDT have been encountered in two categories of patients. Massive haemoptysis has been observed in patients with large obstructive tumours. Some of these patients had also received previous treatments such as radiotherapy or Nd-YAG laser treatment, both of which probably have contributed to the normal tissue damage. In a group of 26 patients, Sutedja et al. [41] encountered four who suffered from pulmonary haemorrhage at times varying from 1.5 months to 6 months after treatment. Each of the patients suffered from tumour progression at the time of bleeding and the authors could not attribute these haemorrhages to PDT alone [41]. The second major complication (respiratory distress) observed in patients whose pulmonary reserve was seriously limited can be prevented by careful selection of patients [39]. The PDT treatment causes edema and sometimes obstruction of the airway by swelling of necrotic tumour. There is a clear need for the removal of this necrotic debris, preferably within two days after illumination. The majority of patients that suffer from a limited pulmonary reserve as a consequence of pneumonectomy should not be treated with PDT. However, PDT either as a single therapeutic method or in addition to surgery, has a place in the treatment of other patients with limited cardiopulmonary reserves (not resulting from pneumonectomy), allowing for maximal preservation of pulmonary function.

Careful protection and explicit instruction to avoid sunlight have decreased the frequency of general skin photosensitivity, which was initially reported to occur in $25-35 \%$ of the patients [44]. Almost all patients are able to resume normal daily activity, 4 to 8 weeks after injection of hematoporphyrin.

\section{Photodynamic therapy for the treatment of malignant and non-malignant skin diseases}

\subsection{Introduction and early clinical results}

Skin cancer is by far the most common of all malignancies. In the United States alone there are more than 800,000 new 
non-melanoma skin cancers each year. The incidence is rising with the current generation's pattern of increasing recreational sun exposure, and also with the decrease in protection by the ozone layer in the atmosphere. For the treatment of these malignancies, there are several existing therapeutic modalities. These include (in order of decreasing efficacy) Moh's surgery, conventional excisional surgery, radiation therapy, curettage and electrodesiccation, and cryotherapy. Unfortunately these therapies also have drawbacks. They often cause significant morbidity (both in healing, and in cosmetic or functional outcome) and they usually have limitations in the ability to treat multiple lesions with high efficacy. Finally, treatment can be expensive.

Over the past 10 years, PDT with systemic Photofrin $®$ has been used for multiple types of cutaneous and subcutaneous malignancies including basal cell carcinoma $[7,45]$, widespread Bowen's disease [45-47], squamous cell carcinoma [48-52], metastatic and recurrent breast carcinoma [50,51,53-55] and Kaposi's sarcoma [56]. In a few instances PDT has also been used for palliation of metastatic melanoma $[50,51,54]$. There is also experience with PDT on patients with non-malignant lesions such as psoriasis $[57,58]$ as an alternative to psoralen UVA and encouraging results have been reported on the treatment of laryngeal warts [59].

By far, basal cell carcinomas have been the most numerous of all tumours treated with PDT. Unfortunately between the various studies reported, the treatment parameters such as drug dose, light dose, anatomical location and histological type have varied greatly. Nevertheless, for primary lesions involving the skin, investigators report high (>80\%) complete response rates that are often durable, combined with excellent cosmetic results.

\subsection{Topical photosensitizer application}

The skin is the largest organ of our body. It is readily accessible to the light that is required for photosensitizer activation and also permits the use of a topical formulation of a photosensitizer. In this way, treatment selectivity can be naximized and the general skin-photosensitivity associated with the use of Photofrin $B^{8}$ avoided. Tetraphenylporphineetrasulphonate ( $\mathrm{TPPS}_{4}$ ) has been evaluated for this purpose. A complete response rate of $93.5 \%$ and a two year recurrence rate of $18-20 \%$ has been reported [60]. Currently the focus or topical photosensitizers is on ALA. ALA is the metabolic precursor to protoporphyrin IX (PpIX) in the biosynthetic pathway for haem. In contrast to ALA, PpIX is photodynamically active and so can act as an endogenous photosenitizer. Because of its high polarity, topical application of ALA will result in an increased penetration in abnormal skin, where the stratum corneum is damaged, as opposed to normal kin with an intact stratum corneum. Depending on the rate if conversion of ALA to PpIX and similarly of PpIX to haem, it temporary accumulation of the photosensitizer can occur. Numerous investigators have examined topical ALA-PDT for superficial carcinomas with varying degrees of success ranging from $50 \%$ to almost $100 \%$ [61-66]. The differences in response rates are probably due to differences in treatment protocol and patient selection criteria. Topical therapy seems to be less effective on thick lesions, or those which are covered by a layer of normal epidermis [61,63]. In such cases multiple treatments with ALA-PDT may be effective [64]. An interesting new development is the use of ALA-PDT for cutaneous T-cell lymphoma [64,67] aimed at selectively clearing skin of malignant lymphocytes.

\section{Photodynamic therapy in the treatment of upper aerodigestive tract disease}

\subsection{Introduction and first clinical results}

In the upper aerodigestive tract, PDT is used for treatment of malignant neoplasms and occasionally for benign lesions such as papillomas of the larynx. The former comprise about $5 \%$ of all malignancies in Western Caucasian people and consist, for ninety percent, of squamous cell carcinomas arising from the surface epithelium [68]. The maximum incidence occurs between 50 and 70 years of age and intake of alcohol and tobacco consumption are recognized as facilitating etiologic factors [69]. This also implies that in some of these patients, the whole mucosal lining of the upper aerodigestive tract is "condemned" and frequently deteriorates into cancer, so-called "field cancerization" [70]. Furthermore, in $10-20 \%$ of the patients treated for primary carcinoma, secondary malignancies in the head and neck area can be detected at the time of first treatment or during follow up $[71,72]$. Most of these so-called "secondaries"' are detected in the early stage, e.g. carcinoma in situ or microinvasive carcinoma [73].

Traditionally the therapy of head and neck cancer consists of surgery and/or radiotherapy and gives an overall cure rate of only $55-65 \%$. In addition to these low cure rates, the interventions often cause serious mutilation. Therefore, there is a continuing search for other, effective and less mutilating therapeutic modalities. Can PDT offer a meaningful contribution in this field?

The first report of PDT for head and neck cancer dates from 1982. Wile and coworkers [74] described a 75\% (complete and partial) response of locally recurrent carcinomas located on various sites in the upper aerodigestive tract. After previous radiotherapy, areas treated with PDT healed well and even repeated applications of this treatment were tolerated well. Bulky tumours showed a lower cure rate $[75,76]$. The most favourable responses were obtained in early superficial disease, whereas neck metastases responded poorly [77]. Good palliation and an occasional cure were described by some authors in cases of advanced local recurrence [78], others could not confirm the role of PDT as a valuable tool for palliation [79], however, treatment of condemned mucosa appeared to be successful [79]. Small carcinomas in the oral and oropharyngeal regions (frequently recurrent dis- 
ease) had a tendency to regrow after PDT, possibly as a consequence of underestimation of tumour infiltration [79]. In a series of PDT treatments of vocal cord carcinoma with involvement of one side only, a response rate of $72 \%$ was achieved during a follow up of $1-4$ years [80]. Monnier et al. [81] and Moghissi et al. [82] obtained good results with photodynamic therapy in the treatment of very superficial lesions such as carcinoma in situ and microinvasive carcinoma. In geometrically complex locations where homogeneous illumination of the target area is difficult to achieve, the rate of recurrence increases. To avoid an insufficient light dose, Biel et al. treated tumours of $3 \mathrm{~mm}$ in thickness or more with interstitial PDT, often in conjunction with surface illumination [83]. Overall it appears that good estimation of tumour thickness, proper exposure of the target volume and great care in light dosimetry and drug dosage are the most important factors to determine success or failure of PDT in the upper aerodigestive tract.

Monnier et al. [81] reported on PDT-induced tissue damage in normal mucosa which received a rather low drug/light dose; in addition, some cases were reported of cicatricial stenosis and fistula attributable to the lack of tumor selectivity of $\mathrm{HpD}$. Using a dose of $2 \mathrm{mg} \mathrm{kg}^{-1} \mathrm{bw}^{-1}$ i.v. Photofrin $B$, Overholt et al. showed that it is possible to induce selective necrosis of mucosa without damaging the underlying muscle [84]. PDT used in this way may have potential for treatment of large areas of dysplasia as in Barret's oesophagus. In this disease, which is caused by gastro-oesophageal reflux, there is a metaplastic change from squamous epithelium to columnar epithelium in the lower oesophagus. It is regarded as a premalignant condition, particularly if dysplasia is present [85]. As only the mucosa is affected (so the problem is limited in depth) PDT can offer an attractive alternative for radical oesophageal resection. Using Photofrin $\circledast(2 \mathrm{mg} \mathrm{kg}$. bw ${ }^{-1}$ ) or ALA ( $60 \mathrm{mg} \mathrm{kg}^{-1} \mathrm{bw}^{-1}$ orally) and optical irradiation with light of $630 \mathrm{~nm}\left(100-200 \mathrm{~J} \mathrm{~cm}^{-2}\right)$, treatment resulted in partial, sometimes complete replacement of Barret's mucosa with normal squamous epithelium $[84,86]$. Whether the cancer risk is also removed by PDT treatment of Barret's oesophagus remains to be established.

\subsection{New sensitizers}

A number of second generation photosensitizers have already been applied in PDT for head and neck cancer. Savary et al. [87] presented preliminary results obtained with metatetrahydroxyphenyl chlorin (m-THPC). m-THPC has an absorption peak at $652 \mathrm{~nm}$. It is effective at low drug and light doses eg. $10 \mathrm{~J} \mathrm{~cm}^{-2}, 48 \mathrm{~h}$ after i.v. administration of $0.3 \mathrm{mg} \mathrm{kg}^{-1} \mathrm{bw}^{-1}$. Based on fluorescence microscopy studies of biopsies of healthy mucosa and early upper aerodigestive cancer, a delay of four days between drug delivery and illumination was suggested to obtain an optimal tumour/ normal tissue ratio of m-THPC. 16 early carcinomas in the upper aerodigestive tract were treated with m-THPC: 14 lesions showed a complete response without regrowth in a 6 months follow-up [88]. In addition, subsequent skin photosensitivity was 6 weeks at the most. m-THPC can be activated at a number of wavelengths eg. 514 and $652 \mathrm{~nm}$. At the same light and drug dose, the latter wavelength may cause deeper necrosis by its deeper tissue penetration in combination with the larger molecular absorption coefficient of m-THPC at 652 $\mathrm{nm}$, as compared with $514 \mathrm{~nm}$. Using m-THPC and light of wavelength $652 \mathrm{~nm}$ in a patient with superficial carcinoma in the oesophagus, led to the development of an oesophagotracheal fistula. For a more superficial effect $514 \mathrm{~nm}$ illumination seems to be preferable [89]. In testing the normal tissue tolerance, Monnier et al. reported a wide inter-individual variation in tumour response and in the duration of skin photosensitivity. A multicentre European study to evaluate the application of $\mathrm{m}$-THPC in PDT of early head and neck cancer is presently being organized [90].

Photosensitization by the endogenous production of protoporphyrin IX (PpIX) through administration of ALA has also been applied in head and neck surgery on an experimental basis. Topical application of ALA on skin tumours led to the production of sufficient PpIX to induce a tumouricidal effect following illumination with light of $630 \mathrm{~nm}$ [61]. After oral administration of ALA to patients with squamous cell carcinomas of the oral cavity, maximal fluorescence of tumour and dysplastic epithelium occurred 4 to 6 hours after administration. Necrosis of malignant tissue in response to ALAPDT was apparent [91]. The same group also reported on the PDT of severe dysplasia and intraepithelial carcinomas of the oral cavity with orally administered ALA. In 10 patients, they demonstrated full thickness epithelial necrosis and subsequent good healing following illumination [92]. In both reports, a transient rise of liver enzymes as a result of oral ALA was reported, returning to a normal level within seven days. The main advantage of using oral ALA induced PpIX photosensitization is the rapid clearance of the sensitizer (1-2 days). This way, repeated treatments using short time intervals might be feasible.

\subsection{Other applications}

Intraoperative photodynamic therapy (IOPDT) [78] has shown to result in larger tumour-free margins in case of minimal persistent or residual disease after ablation [93,94]. In 5 patients, all of whom had previously undergone extensive conventional treatment, PDT of the entire tumour resection bed was performed intraoperatively. The irradiated areas included the carotid artery and the internal jugular vein. All uninvolved skin was covered and excessive exposure to light by operating theatre lamps was avoided by using surgical head-mounted lamps during the surgical resection. Healing occurred without complication and preliminary results indicate a disease-free follow-up of 18 months in all cases [94].

Besides squamous cell carcinomas, other malignancies in the upper aerodigestive tract have also been treated with PDT. Five patients with Kaposi's sarcoma of the oral cavity causing symptoms of dysphagia and interference with speech were 
treated with PDT using Photofrin ${ }^{8}$. Surface illumination as well as interstitial photodynamic therapy were used. All patients achieved symptomatic relief, three of them showing a complete remission during 3-7 months [56]. Additionally, the use of PDT was mentioned in three cases of mucosal melanomas of the upper aerodigestive tract. Using interstitial and surface illumination, no local regrowth was noticeable during the observation period of 12-18 months [83].

Occasionally, PDT has been applied in benign disease such as recurrent laryngeal papillomatosis [95]. Recent reports indicate variable efficacy for PDT in this disease. During a four year follow-up more than half of a group of 25 patients remained free of relapse of these virally induced lesions $[96,97]$. Biel et al. however, mentions a recurrence rate of $100 \%$ in five patients [83].

\section{Summary and perspectives}

Photofrin (\$ based PDT of superficial bladder cancer has severe side effects and long term follow-up results are at present no better than for conventional methods. However, there are many ways to improve existing treatment protocols. Permanent bladder contraction may be prevented by optimizing therapeutic ratios by lowering the Photofrin $\otimes$ dose from 2 to 1.5 , or even $1 \mathrm{mg} \mathrm{kg}^{-1} \mathrm{bw}^{-1}$ and by standardized application of in situ dosimetry. Improvement of therapeutic ratios however, may also be obtained by using second generation photosensitizers. Photosensitization by installation of ALA is very promising in this respect. In addition, topical application of a photosensitizer to some extent circumvents the regulatory problems associated with the intravenous administration of a new drug.

For early-stage lung cancer, Photofrin $\otimes$ based PDT is a new addition to the standard treatment modalities of surgical resection, radiation therapy and chemotherapy. In the treatment of carcinoma in situ or in treating endobronchial NSCLC in the intramural stage it can be curative. This implies that a more widespread adoption of PDT in the field of lung cancer (but not only there) may depend - at least in part - on screening and early detection of malignant neoplasms. Furthermore, the medical awareness of the tissue sparing properties of this therapy should be enhanced.

In advanced lung or oesophageal cancer, PDT is associated with major complications and is currently at best palliative. In patients with high surgical risk it can provide an alternative to surgical resection or it can diminish the size of resection. Controlled studies are needed to determine whether the long term curative potential of the treatment will be equivalent to that of surgical resection. However, endobronchial obstruction is a common complication of advanced-stage NSCLC. Significant relief is possible with PDT but, due to extensive tumour load, cure can not be expected in this group of patients.

The results of PDT in the treatment of malignant and nonmalignant skin diseases are most encouraging and, using either systemic or topical photosensitizer formulations, this therapy has the potential of becoming the treatment of choice. High complete response rates are reported and cosmetic results especially are often superior to conventional treatment methods. Investigators agree that there is minimal dermal damage and little or no scarring. Improvement of the therapy in this field is primarily sought in decreasing the overall skin photosensitivity after intravenous administration of Photofrin ${ }^{\circledR}$. However, for PDT to become accepted in this field it will have to prove its cost effectiveness in the competition with traditional modalities such as cryo-surgery, excision and curettage/electrodesiccation.

Conventional treatment of head and neck cancer often leads to mutilation. A treatment which effectively eradicates tumours without leaving defects and scars would be an important expansion of the oncologist's armamentarium. The main indication of PDT in the management of head and neck malignancies today is the treatment of superficial disease, e.g. condemned mucosa and intraepithelial or microinvasive carcinoma. Furthermore T1 and T2 carcinomas, as well as superficial recurrences after previous therapy, can be treated but only if reliable information concerning infiltration depth of the tumour, good exposure of the treatment site, adequate light delivery and light and drug dosimetry is available. Then, the advantages of PDT, such as complete restoration of the tissues involved and the possibility to repeat the treatment will prevail. In geometrically complex regions the efficacy of PDT diminishes due to complicated dosimetry. Although the anecdotal data are promising, PDT still has to prove itself more effective in the management of head and neck malignancies than existing therapies, preferably in randomized clinical trials.

General acceptance of PDT by most oncologists has been (and is) hampered for various reasons:

(i) Photodynamic therapy must fit into the specific "culture" of the hospital. The difficulties associated with the development of a new research line in a clinical setting are numerous.

(ii) PDT is especially suited for treatment of early lesions. Therefore, the number of patients eligible for PDT will increase provided the early detection of malignancies improves. Early lesions are in most cases difficult to detect and large-scale screening requires a considerable effort in manpower and money [98].

(iii) Illumination after administration of the photosensitizer requires a medical dye-laser. These devices are very expensive, large, and use and maintenance necessitate the presence of a skilled technician. Furthermore, the complexity of proper light delivery (device-to-fibre coupling, in vitro and in vivo light dosimetry, light scattering properties of various tissues) must not be underestimated.

(iv) A suitable photosensitizer (a pure, single chemical substance, easily and consistently manufactured which does not induce skin phototoxicity) for PDT, approved by regulatory agencies such as the FDA is not yet available. 
Nevertheless, there are arguments to give an affirmative answer to the question whether PDT still can be called "a promising new modality". First, the basic concept of PDT, combining two modalities which are harmless by themselves to obtain a beneficial therapeutic effect, remains attractive. Secondly, there is no significant morbidity associated with PDT; especially not when second generation photosensitizers are used. Wound healing, functional and cosmetic outcome after PDT are often superior to established therapies. Thirdly, every year a large number of new drugs are advanced as potential new photosensitizers in clinical photodynamic therapy. Although the majority of these new drugs will never enter widespread clinical practice, it is certain that the current second generation of photosensitizers will not be the last. Regarding the complex and expensive laser systems needed for illumination: it is clear that light application needed for treatment will have to move into the field of cheaper and less complicated, user-friendly light sources such as diode lasers and non-coherent light sources optimized for PDT. In view of the rapid developments in optoelectronics it is reasonable to assume - especially if there is a demand from the market that within the next decade laserdiodes will be available covering the spectrum from UV to IR at very competitive prices. The developments could be such that in the foreseeable future, a clinician may choose from a variety of photosensitizers and devices, the most optimal combination to treat the malignancy with which he is confronted.

Finally, PDT offers a badly needed new approach in oncology, a field in which established therapies operate close to optimal levels. As for all new treatment modalities, PDT has to prove itself equal (at least) or superior to existing therapies, preferably in randomized clinical trials. A cost-effectiveness study should be an integral part of these trials. In view of the low cost of diode lasers (as compared to more conventional clinical laser systems) and provided that the price of the next generation of photosensitizers will be reasonable, PDT could develop into a very cost effective treatment. Not only in oncology but very likely also in ophthalmology for treatment of macular degeneration and possibly in dermatology for psoriasis and in immunology for the treatment of autoimmune diseases [99].

However, now the FDA has (finally) approved Photofrin $\otimes$ for the largest pharmaceutical market in the world, the US, it is of the utmost importance for the survival of PDT that this therapy proves its right to exist as an established therapy in a clinical setting within the next five to 10 years.

\section{References}

[1] T.J. Dougherty, W.R. Potter and D. Bellnier, Photodynamic therapy for the treatment of cancer: Current status and advances, In D. Kessel (ed.), Photodynamic Therapy of Neoplastic Disease (Vol. I), CRC Press, Boca Raton, FL, 1990, pp. 1-19.

[2] R.S. Wooten, K.C. Smith and D.A. Ahlquist, Prospective study of cutaneous phototoxicity after systemic hematoporphyrin derivative, Lasers Surg. Med., 8 (1988) 294-300.
[3] V.M. Mullooly, A.L. Abramson and M.J. Shikowitz, Dihematoporphyrin-ether induced photosensitivity in laryngeal papilloma patients, Lasers Surg. Med., 10 (1990) 349-356.

[4] N. Razum, O.J. Balchum, A.E. Profio et al., Skin photosensitivity: Duration and intensity following intravenous hematoporphyrin derivatives, HPD and DHE, Photochem. Photobiol., 46 (1987) 925928.

[5] S. Lam, B. Palcic, D. McLean et al., Detection of early lung cancer using low dose Photofrin II, Chest, 97 (1990) 333-337.

[6] B.D. Wilson, T.S. Mang, H. Stoll, C. Jones, M. Cooper and T.J. Dougherty, Photodynamic therapy for the treatment of basal cell carcinoma, Arch. Dermatol., 128 (1992) 1597-1601.

[7] J.C. Kennedy and R.H. Pottier, Endogenous protoporphyrin IX, a clinically useful photosensitizer for photodynamic therapy, $J$. Photochem. Photobiol. B: Biol., 14 (1991) 275-292.

[8] A.M.R. Fisher, A.L. Murphree and C.J. Gomer, Clinical and preclinical photodynamic therapy, Rev. Ser., Lasers Surg. Med., 17 ( 1995) 2-31.

[9] B.J. Lum and F.M. Torti, Adjuvant intravesicular pharmacotherapy for superficial bladder cancer, J. Natl. Cancer Inst., 83 (1991) 682-694.

[10] M.J. Manayak, Photodynamic therapy: principles and urologic applications, Semin. Urol., 9 (1991) 192-202.

[11] A.J. Pope and S.G. Bown, Photodynamic therapy, Br. J. Urol., 68 (1991) 1-9.

[12] U.O. Nseyo, Photodynamic therapy, Urol. Clin. North Am., 19 (1992) 591-599.

[13] D. Jocham, M. Beer, R. Baumgartner, G. Staehler and E. Unsöld, Longterm experience with integral photodynamic therapy of TIS bladder carcinoma, in G. Bock and S. Harnet (eds.), Photosensitizing Compounds: their Chemistry, Biology and Clinical Use, Ciba Foundation Symposium 146, Wiley, Chichester, 1989, pp. 198-208.

[14] J.I. Harty, M. Amin, T.J. Wieman, M.T. Tseng, D. Ackerman and W. Broghamer, Complications of whole bladder dihematoporphyrin ether photodynamic therapy, J. Urol., 141 (1989) 1341-1346.

[15] K. Naito, H. Hisazumi, T. Uchibayashi, T. Amano, A. Hirata, K. Komatsu, T. Ishida and N. Miyoshi, Integral laser photodynamic treatment of refractory multifocal bladder tumours, J. Urol., 146 (1991) 1541-1545.

[16] M.A. D'Hallewin, L. Baert, J.P.A. Marijnissen and W.M. Star, Whole bladder wall photodynamic therapy with in situ light dosimetry for carcinoma in situ of the bladder, J. Urol., 148 (1992) 1152-1155.

[17] T. Uchibayashi, K. Koshida, K. Kunimi and H. Hisazumi, Whole bladder wall photodynamic therapy for refractory carcinoma in situ of the bladder, Br. J. Cancer, 71 (1995) 625-628.

[18] U.O. Nseyo, S.L. Lundahl and D.C. Merrill, Whole bladder photodynamic therapy: critical review of present-day technology and rationale for development of intravesical laser catheter and monitoring system, Urology, 36 (1990) 398-402.

[19] J.P.A. Marijnissen, H. Jansen and W.M. Star, Treatment system for whole bladder wall photodynamic therapy with in vivo monitoring and control of light dose rate and dose, J. Urol., 142 (1989) 1351-1355.

[20] E. Unsöld, W. Beyer, A. Heinze and R. Sroka, Irradiation modalities for photodynamic therapy, Lasers Med. Sci. Suppl. (1989) 159-164.

[21] E. Unsöld, R. Baumgartner, W. Beyer, D. Jocham and H. Stepp, Fluorescence detection and photodynamic treatment of photosensitized tumours in special consideration of urology, Lasers Med. Sci., 5 (1990) 207-212.

[22] J.P.A. Marijnissen, W.M. Star, H.J.A. in 't Zandt, M.A. D'Hallewin and $L$. Baert, In situ light dosimetry during whole bladder wall photodynamic therapy: clinical results and experimental verification, Phys. Med. Biol., 38 (1993) 567-582.

[23] H.J. van Staveren, J.F. Beek, J.W.H. Ramaekers, M. Keijzer and W.M. Star, Integrating sphere effect in whole bladder wall photodynamic therapy. I: $532 \mathrm{~nm}$ versus $630 \mathrm{~nm}$ optical irradiation, Phys. Med. Biol., 39 (1994) 947-959.

[24] M.A. D'Hallewin and L. Baert, Long term results of whole bladder wall photodynamic therapy for carcinoma in situ of the bladder, Urology, 45 (1995) 763-767. 
[25] D. Jocham, personal communication, 1996.

[26] A.J. Pope and S.G. Bown, The morphological and functional changes in rat bladder following photodynamic therapy with phthalocyanine photosensitization, J. Urol., 145 (1991) 1064-1070.

[27] K. Taari, M. Talja, M. Riihelä, S. Ranniko and R. Mokka, Morphological effects of photodynamic therapy on rabbit bladder using Photofrin II and Photosan intravesically and intravenously, $B r$. J. Urol., 70 (1992) 616-621.

28] M. Kriegmair, R. Baumgartner, S. Stocker, R. Riesenberg, A. Hofstetter, R. Knüchel and P. Steinbach, Photodynamic therapy of urothelial cancer following intravesical application of 5aminolevulinic acid in a rat bladder tumour model, J. Urol., 151 (1994) 518A.

29] M. Kriegmair, R. Baumgartner, W. Lumper, R. Waidelich, A. Hofstetter, Early clinical experience with 5-aminolevulinic acid for photodynamic therapy of superficial bladder cancer, submitted to $\mathrm{Br}$. J. Urology.

30] I. Eder, A. Stenzl, H. Kostron, G. Bartsch, H. Klocker, Elektromotive diffusion (EMD) and photodynamic therapy with $\delta$-aminolevulinic acid (ALA) for superficial bladder cancer, J. Urology, 153 (1995) 234A.

31] R. Baumgartner, H. Fisslinger, D. Jocham, H. Lenz, L. Ruprecht, H. Stepp and E. Unsöld, A fluorescence imaging device for endoscopic detection of early stage cancer-instrumental and experimental studies, Photochem. Photobiol., 46 (1987) 759-763.

32] L. Baert, R. Berg, B. van Damme, M.A. D'Hallewin, J. Johansson, K. Svanberg and $\mathrm{S}$. Svanberg, Clinical fluorescence diagnosis of human bladder carcinoma following low dose Photofrin injection, Urology, 4 ( 1993) 322-330.

33] M. Kriegmair, R. Baumgartner, W. Lumper, R. Riesenberg, S. Stocker and A. Hofstetter, Fluorescence cystoscopy following intravesical instillation of aminolevulinic aid (ALA), J. Urol., 149 (1993) 240A.

34] M. Kriegmair, R. Baumgartner, R. Knüchel, H. Stepp, F. Hofstädter, A. Hofstetter, Detection of early bladder cancer by 5 -aminolevulinic acid induced porphyrin fluorescence, $J$. Urology, in press.

35] J.B. Mitchell et al., Biological basis for phototherapy, in G. Morstyn and A.H. Kaye (eds.), Phototherapy of Cancer, Harwood Academic Publishers, Chur, 1990, pp. 1-22.

36] H. Kato et al., Photodynamic therapy of early-stage lung cancer, in G. Bock and S. Hamet (eds.), Photosensitizing compounds: their chemistry biology and clinical use, Ciba Foundation Symposium 146, Wiley, Chichester, 1989, pp. 183-194.

37] H. Kato, Photodynamic therapy of early cancer, in G. Morstyn, A.H. Kaye, (eds.), Phototherapy of Cancer, Harwood Academic Publishers, Chur, 1990, pp. 133-151.

38] D.A. Cortese and J.H. Kinsey, Endoscopic management of lung cancer with hematoporphyrin derivative phototherapy, Mayo Clin. Proc., 57 ( I982) 543-547.

39] E.S. Edell and D.A. Cortese, Bronchoscopic phototherapy with hematoporphyrin derivative for treatment of localized bronchogenic carcinoma: a five-year experience, Mayo Clin. Proc., 62 (1987) 8-14.

40] E.S. Edell and D.A. Cortese, Bronchoscopic localization and treatment of occult lung cancer, Chest, 96 (1989) 919-924.

41] G. Sutedja, P. Baas, F.A. Stewart and N. van Zandwijk, A pilot study of photodynamic therapy in patients with inoperable non-small cell lung cancer, Eur. J. Cancer, $28 a$ (1992) 1370-1373.

42] K. Furuse, M. Fukuoka, H. Kato et al., A prospective phase II study on photodynamic therapy with Photofrin II for centrally located earlystage lung cancer, J. Clin. Oncol., II (1993) 1852-1857.

43] N. van Zandwijk, T. Sutedja, P. Baas and F. Stewart, An emerging role for photodynamic therapy in lung cancer, Form. Trends Exp. Clin. Med., 3 ( 1993) 33-39.

44] T.J. Dougherty et al., Cutaneous phototoxic occurrences in patients receiving photofrin, Lasers Surg. Med., 10 (1990) 485-488.

45] J.S. McCaughan, J.T. Guy, W. Hicks, L. Laufman, T.A. Nims and J. Walker, Photodynamic Therapy for Cutaneous and Subcutaneous Malignant Neoplasms, Arch. Surg., 125 (1989) 211-216.
[46] P.J. Robinson, J.A.S. Carruth and G.M. Fairris, Photodynamic therapy: a better treatment for widespread Bowen's disease, Br. J. Dermatol., II9 (1988) 59-61.

[47] C. Jones, M. Cooper, T. Mang, B.D. Wilson and H.L. Stoll, Photodynamic Therapy in the Treatment of Unusual Bowen's Disease, J. Am. Acad. Dermatol., 27 (1992) 979-982.

[48] B.D. Wilson, T.S. Mang, M. Cooper and H. Stoll, Use of Photodynamic Therapy for the Treatment of Extensive Basal Cell Carcinomas, Facial Plast. Surg., 6 (1989) 185-189.

[49] D.G. Pennington, M. Waner and A. Knox, Photodynamic Therapy for Multiple Skin Cancers, Plast. Reconstr. Surg., 82 (1988) 1067-1071.

[50] J.S. McCaughan Jr., J.T. Guy, W. Hicks, L. Laufman, T.A. Nims and J. Walker, Photodynamic Therapy for cutaneous and subcutaneous malignant neoplasms, Arch. Surgery, /24 (2), (1989) 211-216.

[51] D. Gilson, D. Ash, I. Drirer, J.W. Feather and S. Brown, Therapeutic ratio of Photodynamic Therapy in the Treatment of Superficial Tumours of Skin and Subcutaneous Tissues in Man, Br. J. Cancer, 68 (1988) 665-667.

[52] D.J. Gross, M. Waner, R.H. Schosser and S.M. Dinehart, Squamous Cell Carcinoma of the Lower Lip Involving a Large Cutaneous Surface, Photodynamic Therapy as an Alternative Therapy, Arch. Dermatol., I26 (1990) 1148-1150.

[53] T.J. Dougherty, Photoradiation Therapy for Cutaneous and Subcutaneous Malignancies, J. Invest. Dermatol., 77 ( 1981) 122-124.

[54] G. Bandieramonte, R. Marchesini, E. Melloni, C. Andreoli, S. di Pietro, P. Spinelli, G. Fava, F. Zunino and H. Emanuelli, Laser Phototherapy Following HpD Administration in Superficial Neoplastic Lesions, Tumouri. 70 (1984) 327-334.

[55] M. Shuh, U.O. Nseyo, W.R. Potter, T.L. Dao and T.J. Dougherty, Photodynamic Therapy for Palliation of Locally Recurrent Breast Carcinoma, J. Clin. Oncol., 5 (1987) 1766-1770.

[56] V.G. Schweitzer, D. Visscher, Photodynamic Therapy for Treatment of AIDS-related Oral Kaposi's Sarcoma, Otolaryngol. Head Neck Surg., I02 (1990) 639-649.

[57] J.L. McCullogh, G.D. Weinstein, J.L. Douglas and M.W. Berns, Photosensitizers in dermatology, Photochem. Photobiol., 46 (1987) $77-82$.

[58] G.D. Weinstein, J.L. McCullough, J.S. Nelson and M.W. Berns, Low dose Photofrin II photodynamic therapy of psoriasis, $J$. Invest. Dermatol., 96 (1991) 573.

[59] A.L. Abramson, M.J. Shikowitz, V.M. Mullooly, B.M. Steinberg, C.A. Amella and H.R. Rothstein, Clinical effects of photodynamic therapy on recurrent laryngeal papillomas, Arch. Otolaryngol. Head Neck Surg., 118 (1992) 25-29.

[60] O. Santoro, G. Bandieramonte, E. Melloni, R. Marchesini, F. Zunino, P. Lepera and G. De Palo, Photodynamic therapy by topical metetetraphenylporphinesulphonate tetrasodium salt administration in superficial basal cell carcinomas, Cancer Res., 50 (1990) 4501-4503.

[61] J.C. Kennedy and R.H. Pottier, Endogenous protoporphyrin IX, a clinically useful photosensitizer for photodynamic therapy, $J$. Photochem. Photobiol. B: Biol., 14 (1992) 275-292.

[62] P. Wolf, E. Rieger and H. Kerl, Topical photodynamic therapy with endogeneous porphyrins after application of 5-aminolevulinic acid, $J$. Am. Acad. Derm., 28(1) (1993) 17-21.

[63] F. Cairnduff, M.R. Stringer, E.J. Hudson, D.V. Ash and S.B. Brown, Superficial photodynamic therapy with topical 5 -aminolevulinic acid for superficial primary and secondary skin cancer, Br.J. Cancer, 69 (1994) 605-608.

[64] K. Svanberg, T. Anderson, D. Killander, I. Wang, U. Stenram, S. Andersson-Engels, R. Berg, J. Johansson and S. Svanberg, Photodynamic therapy of non-melanoma malignant tumours of the skin using topical $\delta$-aminolevulinic acid sensitization and laser irradiation, Br. J. Dermatol., 130 ( 1994) 743-751

[65] H. Lui, N. Kollias, J. Wimberly, S. Salasche, D. McLean and R. Anderson, Photodynamic therapy of nonmelanoma skin cancer with 5-aminolevulinic acid and visible light: a clinical and histological study, Proc. Ann. Meet. Am. Soc. Photobiol., (1994) 59s, 71 s. 
[66] S.D. Shanler, W. Wan, J.E. Whitaker, T.S. Mang, C. Jones, B.D. Wilson, H. Stoll and A.R. Oseroff, Photodynamic therapy with topical $\delta$-aminolevulinic acid for treatment of cutaneous carcinomas and cutaneous T-cell lymphoma, J. Invest. Dermatol., I0I (1993) 406a.

[67] P. Wolf, R. Fink-Puches, L. Cerroni and H. Kerl, Photodynamic therapy for mycosis fungoides after topical photosensitisation with 5aminolevulinic acid, J. Am. Acad. Derm., 31 (1994) 678-680.

[68] D.R. Gnepp (ed.), Pathology of the Head and Neck, Churchill, Livingstone, New York, 1988, pp. 266-284.

[69] J.G. Batsakis (ed.), Tumours of the Head and Neck. Clinical and Pathological Considerations, 2nd edn., William and Wilkins, Baltimore, M.D., 1979, pp. 144-177.

[70] D.P. Slaughter, H.W. Southwick and W. Smejkal, "Field cancerization' in oral stratified squamous epithelium: clinical implications of multicentric origin, Cancer, 6 (1953) 963-968.

[71] N. de Vries, Second primary tumours in laryngeal cancer, Acta Otorhinolaryngol-Belg., 46 (1992) 153-159.

[72] N. de Vries, I. van de Waal and G.B. Snow, Multiple primary tumours in oral cancer, Int. J. Oral Maxillofac. Surg., 15 (1986) 85-87.

[73] R. Pasche, M. Savary and Ph. Monnier, Multiple squamous cell carcinoma of the upper digestive and lower respiratory tracts: methodology of endoscopic screening, Acta Endoscopica, 11 (1981) 277-291.

[74] A.G. Wile, A. Dahlman A, R.G. Burns and M.W. Berns, Laser photoradiation therapy of cancer following hematoporphyrin sensitization, Lasers Surg. Med., 2 (1982) 107-127.

[75] A. Dahlman, A.G. Wile, R.G. Burns, R. Mason, F.M. Johnson and M.W. Berns, Laser photoradiation therapy of cancer, Cancer Res., 43 (1983) 430-434.

[76] L.I. Grossweiner, J.H. Hill, R.V. Lobraico, Photodynamic therapy of head and neck squamous cell carcinoma: optical dosimetry and clinical trial, Photochem. Photobiol., 46 (1987) 911-917.

[77] G.S. Keller, D.R. Doiron and G.U. Fisher, Photodynamic therapy in otolaryngology- Head and Neck Surgery, Arch. Otolaryngol., 111 (1985) $758-761$.

[78] D.E. Schuller, J.S. McCaughan and R.P. Rock, Photodynamic therapy in head and neck cancer, Arch. Otolaryngol, 111 (1985) 351-355.

[79] J.L. Gluckman, Hematoporphyrin photodynamic therapy: Is there truly a future in head and neck oncology? Reflections of a 5 year experience, Laryngoscope, 101 (1991) 36-42.

[80] C. Freche and S. De Corbiere, Use of photodynamic therapy in the treatment of vocal cord carcinoma, J. Photochem. Photobiol. B: Biol., 6 (1990) 291-296.

[81] Ph. Monnier, M. Savary, Ch. Fontolliet, G. Wagnieres, A. Chatelain, P. Cornaz, Ch. Depeursinge and H. van den Bergh, Photodetection and photodynamic therapy of "early" squamous cell carcinoma of the pharynx, oesophagus and tracheo-bronchial tree, Lasers Med. Sci., 5 (1990) 149-169.

[82] K. Moghissi, K. Dixon, E. Hudsun and M. Stringer, Photodynamic therapy (PDT) of Oesophageal cancer, Lasers Med. Sci., 10 (1995) 67-71.

[83] M.A. Biel, Photodynamic therapy and the treatment of primary malignancies of the head and neck, in 5th. Int. Photodynamic Association Biennial Meeting, September 21-24, 1994, FL, USA, Abstract 100.

[84] B. Overholt, M. Panjehpour, E. Tefftelar and M. Rose, Photodynamic therapy for treatment of early adenocarcinoma in Barret's esophagus, Gastrointest. Endoscop., 39, (1) (1993) 73-76.
[85] H.G. Schmidt, R.H, Riddell, B. Walter, D.B. Skinner and J.F. Riemann, Dysplasia in Barret's esophagus, J. Cancer Res. Clin. Oncol., 110 (1985) 145-152.

[86] H. Barr, T. Dix, D. Roberts and N. Shepard, Eradication of high grade dysplasia in columnar lined (Barret's) oesophagus by photodynamic therapy with oral 5 -aminolevulinic acid and $630 \mathrm{~nm}$ light, Gut. 35 . (Suppl. 5), (1994) 7.

[87] J.F. Savary, Ch. Fontolliet, D. Braichotte, Ph. Monnier and H. van den Bergh, Detection by fluorescence microscopy of the localization and time dependent mTHPC. Distribution in biopsies of bronchi, oesophagus and pharynx, in 5th Int. Photodynamic Association Biennial Meeting, September 21-24, 1994, FL, USA, Abstract, p. 37.

[88] J.F. Savary, Ch. Fontolliet, D. Braichotte, Ph. Monnier and H. van den Bergh, First clinical results after photodynamic treatment of early squamous cell carcinomas of the oesophagus, bronchi and mouth with meta-tetrahydroxyphenyl chlorin ( $\mathrm{m}$-THPC), in 5th Int. Photodynamic Association Biennial Meeting, September 21-24, 1994, FL, USA, Abstract 27.

[89] $\mathrm{Ph}$. Monnier, J.F. Savary, G. Wagnieres, H. van den Bergh, J. Mizeret and $\mathrm{Ch}$. Fontolliet, Green light $(514 \mathrm{~nm}$ ) irradiation for the prevention of complications in PDT of early squamous cell carcinomas of the oesophagus, in 5th Int. Photodynamic Association Biennial Meeting. September 21-24, 1994, FL, USA, Abstract 28.

[90] M.G. Dilkes and M.L. DeJode, m-THPC mediated PDT. Experience and thoughts after 17 treatments, in D.A. Cortese (ed.) 5 th Int. Photodynamic Association Biennial Meeting, Proc. SPIE., 2371 (1995) 256-261.

[91] W.E. Grant, C. Hopper, A.J. MacRobert, P.M. Speight and S.G. Bown, Photodynamic therapy of oral cancer: photosensitization with systemic aminolaevulinic acid, Lancet, 342 (1993) 147-148.

[92] C. Hopper, K. Fan, W.E. Grant, P.M. Speight and S.G. Bown, Photodynamic therapy using 5-aminolaevulinic acid in oral malignancy and premalignancy, in D.A. Cortese (ed.), 5 th Int. Photodynamic Association Biennial Meeting, Proc. SPIE, 2371 (1995) 254-255.

[93] M.A. Biel, Photodynamic therapy and the treatment of neoplastic diseases of the larynx, Laryngoscope, 104 (1994) 399-403.

[94] M.A. Biel, Photodynamic tyherapy as an adjuvant intraoperative treatment of recurrent head and carcinomas, in 5th Int. Photodynamic Association Biennial Meeting. September 21-24, 1994 FL, USA, Abstract 101

[95] A.L. Abramson, M.J. Shikowitz, V.M. Mullooly, B.M. Steinberg and R.B. Hyman, Variable light dose effects on photodynamic therapy for laryngeal papillomas, Arch. Otolaryngol. Head and Neck Surg., 120 (1994) 852-855.

[96] J. Feyh, A. Gutmann and A. Leunig, Photodynamic therapy in head and neck surgery, Laryngo Rhino Otol, 72 (1993) 273-278.

[97] J. Feyh, Photodynamic therapy of malignant and nonmalignant tumours in head and neck surgery. Results of a clinical study, in 5 th Int. Photodynamic Association Biennial Meeting, September 21-24 1994, FL, USA, Abstract 103.

[98] T.J. Dougherty, Photodynamic therapy for early stage lung cancer, Chest, I02 (5), (1992) 1314-1315.

[99] J.G. Levy, The preclinical and clinical development of Photofrin $\$$ and benzoporphyrin derivative: $A$ reflection on opportunities and challenges, J. Photochem. Photobiol. B: Biol., 30 (1995) 79-82. 